\title{
The Value of Telemedicine for the Follow-up of Patients with New Onset Type 1 Diabetes Mellitus During COVID-19 Pandemic in Turkey: A Report of Eight Cases
}

\author{
(D) Ferda Evin, (D) Eren Er, (1) Aysun Ata, (D) Arzu Jalilova, (1) Günay Demir, (1) Yasemin Atik Altınok, (1) Samim Özen, (D) Şükran Darcan, \\ (D) Damla Gökşen
}

Ege University Faculty of Medicine, Department of Pediatrics, Division of Pediatric Endocrinology, Izmir, Turkey

\begin{abstract}
What is already known on this topic?
The use of telemedicine systems reduce glycemic variability parameters including coefficient of variation and standard deviation values. Using telemedicine, the time in range may be achieved at recommended levels in children with type 1 diabetes (T1D).
\end{abstract}

\section{What this study adds?}

Good glycemic control can be achieved by negating the effect of the pandemic on accessibility of diabetic services with telemedicine in T1D.

\begin{abstract}
The current Coronavirus disease-2019 (COVID-19) pandemic has forced health care teams to look for alternative approaches to manage a great number of children with diabetes, not only in rural but also in urban locations. The aim was to assess the provision of information about follow-up of new-onset pediatric type 1 diabetes (T1D) patients, and to investigate the integration of telemedicine into routine clinical care in the long term. The changes in coefficient of variation (CV), standard deviation and percentages of time in range (TIR), time below range (TBR) and time above range were evaluated in eight children with new-onset T1D, diagnosed during the COVID-19 pandemic. The study period was two-months of follow-up using a telemedicine system. Median follow-up time was 51 (24-66) days. Two of the patients were using low glucose suspend system and six were on multiple daily injection therapy. Target TIR values were achieved in seven patients in the last televisit and, in line with recent guidelines, a TBR $<70 \mathrm{mg} / \mathrm{dL}$ ( $<3.9 \mathrm{mmol} / \mathrm{L})$ (level 1 hypoglycemia) of $<4 \%$ and a TBR $<54 \mathrm{mg} / \mathrm{dL}$ ( $<3.0 \mathrm{mmol} / \mathrm{L}$ ) (level 2 hypoglycemia) of $<1 \%$ were achieved in all patients. Seven patients achieved a $\mathrm{CV}$ of $<36 \%$ at their last televisit. Telemedicine as an alternative follow-up tool during unusual circumstances such pandemics, even in countries where it is not routinely used, could be beneficial to achieve optimum glycemic control in patients with new-onset T1D.

Keywords: Type 1 diabetes, telemedicine, COVID-19, technology, sensor augmented pump
\end{abstract}

\section{Introduction}

Telemedicine can be defined as "the remote delivery of healthcare services". It allows patients and physicians to communicate in real-time $(1,2)$. The current Coronavirus disease-2019 (COVID-19) pandemic has forced health care teams to look for alternative approaches to manage a great number of children with diabetes, not only in rural but also in urban locations. Managing patients with new-onset type
1 diabetes (T1D) is acknowledged as a clinical challenge, and when this occurs during the current pandemic the challenges are magnified.

Data on the use of telehealth in patients with diabetes is encouraging (3). Telemedicine has been associated with improved cost-effectiveness and patient satisfaction (4). A study run with school children showed the benefits of telemedicine communication between the school nurse and
Address for Correspondence: Ferda Evin MD, Ege University Faculty of Medicine, Department of Pediatrics, Division of Pediatric Endocrinology, İzmir, Turkey

Phone: +90232 3901230 E-mail: ferdaevin88@gmail.com ORCID: orcid.org/0000-0001-7169-890X
Conflict of interest: None declared Received: 21.07.2020 Accepted: 08.10.2020

${ }^{\circ}$ Copyright 2021 by Turkish Pediatric Endocrinology and Diabetes Society

The Journal of Clinical Research in Pediatric Endocrinology published by Galenos Publishing House. 
the diabetes team, in addition to the children's regular care. The telemedicine group had lower hemoglobin A1c (HbA1c) which is a marker of metabolic control, improvement in reported quality of life and fewer hospitalizations/ emergency department visits (5). In studies conducted before the pandemic, telemedicine was more successful in adolescents with diabetes with longer duration of diabetes and with higher baseline HbA1c values (6).

In the early days of telemedicine implementing systems could incur high costs (7). Today, less costly smartphones and other devices make this technology accessible and costeffective. The aim was to assess the provision of information about follow-up of new-onset pediatric T1D patients, and to investigate the integration of telemedicine into routine clinical care in the long term.

\section{Case Report}

When the first COVID-19 patient was diagnosed in Turkey on March 11, 2020, four new-onset T1D were in the hospital and they are included in the study. Additionally, during a two month period, nine patients were diagnosed during the COVID-19 pandemic and four of these were included in the study. Five patients were excluded: one did not continue with telemedicine; and four patients were still hospitalized when the manuscript was written. In total eight patients were included in this case series and characteristics of the patients are given in Table 1. Median follow-up time was 51 (24-66) days. Patients with continuous glucose monitoring (CGM)/flash glucose monitoring system (FGMS) were asked to share their glucose profile by using CareLink Personal software version 3.0 (Medtronic, Minneapolis, MN, USA) or FreeStyle LibreLink from homeland. Patients who did not use CGM/FGMS shared their daily self-monitoring of blood glucose (SMBG) measurements by either smartphones/ email. Insulin doses were adjusted by the same diabetes team.

When the cases were evaluated on an individual basis, two of the patients had been admitted with ketoacidosis and were changed to sensor augmented pump (SAP) with predictive low glucose suspend (PLGS) (Minimed 640 $\left.\mathrm{G}^{\circledR}\right)$ after five days of multiple daily insulin (MDI) therapy because of family anxiety about hypoglycemia (case 2 and 3). MDI insulin treatment protocol included a fixed basal insulin administration, subcutaneously, once daily (insulin aspart or detemir) and rapid acting insulin administration (either insulin aspart/glulisin or lispro insulin) before meals with a dosing based on carbohydrate counting and blood sugar concentrations. Insulin doses of the patients are given in Table 2. In case 3, with ongoing education with telehealth, excellent glycemic metrics were achieved with a time in range (TIR) $96.3 \%$, time below range (TBR) $0.5 \%$ and time above range (TAR) $3.2 \%$ by the second week. Cases 1 and 4 were admitted with severe diabetic ketoacidosis (DKA) and were started on MDI therapy and used FGMS Abbott FreeStyle Libre. Insulin doses were adjusted based on the outputs through televisits by the pediatric diabetologist. In case 4 , after one month, she unfortunately stopped regular daily glucose sharing. At her last televisit, TIR decreased to

\begin{tabular}{|c|c|c|c|c|c|c|c|c|}
\hline & Case 1 & Case 2 & Case 3 & Case 4 & Case 5 & Case 6 & Case 7 & Case 8 \\
\hline Age & 6.4 & 9 & 10.7 & 13.7 & 2.3 & 7.4 & 12.6 & 8 \\
\hline Gender & M & M & M & $\mathrm{F}$ & $\mathrm{F}$ & M & M & $\mathrm{F}$ \\
\hline Weight SDS & -0.38 & 0.47 & 2.42 & 0.63 & -0.74 & -1.13 & 0.73 & -1.71 \\
\hline Height SDS & 0.97 & 2.29 & 2.28 & 0.40 & -0.66 & 2.0 & 1.25 & \\
\hline BMI SDS & -1.52 & -1.9 & 1.94 & 0.43 & -0.55 & -5.16 & 0.27 & \\
\hline Diagnosis during COVID-19 pandemic & - & - & - & - & + & + & + & + \\
\hline Clinical presentation & Severe DKA & $\begin{array}{l}\text { Diabetic } \\
\text { ketosis }\end{array}$ & $\begin{array}{l}\text { Severe } \\
\text { DKA }\end{array}$ & Severe DKA & Mild DKA & $\begin{array}{l}\text { Severe } \\
\text { DKA }\end{array}$ & $\begin{array}{l}\text { Diabetic } \\
\text { ketosis }\end{array}$ & $\begin{array}{l}\text { Severe } \\
\text { DKA }\end{array}$ \\
\hline Co-morbidity & - & - & - & $\begin{array}{l}\text { Hashimoto } \\
\text { thyroiditis }\end{array}$ & - & - & $\begin{array}{l}\text { Asthma } \\
\text { depression }\end{array}$ & - \\
\hline Anti-GAD (iU/mL) & $>120$ & $>120$ & 14.06 & $>120$ & $>120$ & 3.81 & 49.1 & 0.7 \\
\hline Anti-insulin autoantibody (U/mL) & 2.12 & 3.6 & - & 3.06 & 10.44 & 2.75 & 2.56 & 2.37 \\
\hline Hospitalization (days) & 25 & 27 & 10 & 15 & 7 & 6 & 8 & 12 \\
\hline Follow-up (days) & 62 & 66 & 51 & 65 & 51 & 51 & 24 & 27 \\
\hline Insulin delivery method & MDI & CSII & CSII & MDI & MDI & MDI & MDI & MDI \\
\hline HbA $1 \mathrm{c}$ at diagnosis (\%) & 12.4 & 9.9 & 11.6 & 11.6 & 9.5 & 13.9 & 13.6 & 13.7 \\
\hline C-peptide (nmol/L) & 0.180 & 0.52 & 0.23 & 0.3 & 0.1 & 0.1 & 0.46 & 0.52 \\
\hline
\end{tabular}

SDS: standard deviation score, Anti-GAD: glutamic acid decarboxylase antibody, HbA1 c: glycated hemoglobin A1c, M: male, F: female, COVID-19: Coronavirus disease-2019, BMI: body mass index, MDI: multiple daily insulin, DKA: diabetic ketoacidosis 
$61 \%$, TAR increased to $36 \%$ with TBR $3 \%$. We think that despite using FGMS, the deterioration of metrics may be due to early cessation of televisits.

Case 5 was a 2.3-year-old girl diagnosed with hyperglycemia and mild ketosis. As a result of her young age, and unpredictable eating habits and activity, use of a SAPPLGS was recommended but the family declined due to the expense; SAP-PLGS is not covered by insurance in Turkey. Therefore, MDI treatment was initiated. Since the parents declined learning carbohydrate counting, she was discharged with an exchange meal plan after seven days of hospitalization. The parents also declined using any type of CGM due to financial issues and lack of insurance coverage. For the first 30 days, parents were encouraged to share SMBG measurements every day and family's education continued. Insulin doses were adjusted in consultation with the diabetes team. This patient had the worst glycemic control of the eight cases presented here. In the second week, she had a TIR of $48.7 \%$ but with ongoing education via telemedicine her TIR increased to $81.7 \%$ without any documented level 1 hypoglycemia. Cases 6 and 8 were diagnosed as severe DKA and after one day of pediatric intensive unit hospitalization, MDI treatment was started with SMBG. Case 7 was admitted

Table 2. Total daily insulin doses (IU/kg) of patients at first 2 weeks and last 2 weeks

\begin{tabular}{llll}
\hline & \multicolumn{2}{l}{ Insulin doses (IU/kg) } \\
\cline { 2 - 4 } & Second week & First month & Last control \\
\hline Case 1 & 0.44 & 0.50 & 0.60 \\
Case 2 & 0.36 & 0.44 & 0.57 \\
Case 3 & 0.38 & 0.37 & 0.41 \\
Case 4 & 0.75 & 0.78 & 0.71 \\
Case 5 & 0.91 & 1.08 & 1.07 \\
Case 6 & 1.00 & 0.70 & 0.82 \\
Case 7 & 1.43 & 1.32 & 1.23 \\
Case 8 & 1.23 & 1.15 & 1.19 \\
\hline
\end{tabular}

to the hospital with ketosis and she was again treated with MDI therapy and SMBG.

In all eight patients follow-up visits were scheduled every day for the first 14 days and then every week for the first two months and whenever needed. Glycemic variability (GV) index of the first 14 days after discharge and the last televisit are given in Table 3.

\section{Discussion}

In the late fall of 2019, Wuhan in China announced an outbreak of an infection, which was later designated
COVID-19 by the World Health Organization (WHO) $(8,9)$. COVID-19 was declared pandemic by WHO on March 11, 2020; the date on which the first positive case was detected in Turkey.

COVID-19 has required dramatic changes to our delivery of health care, some of which improved access and outcomes

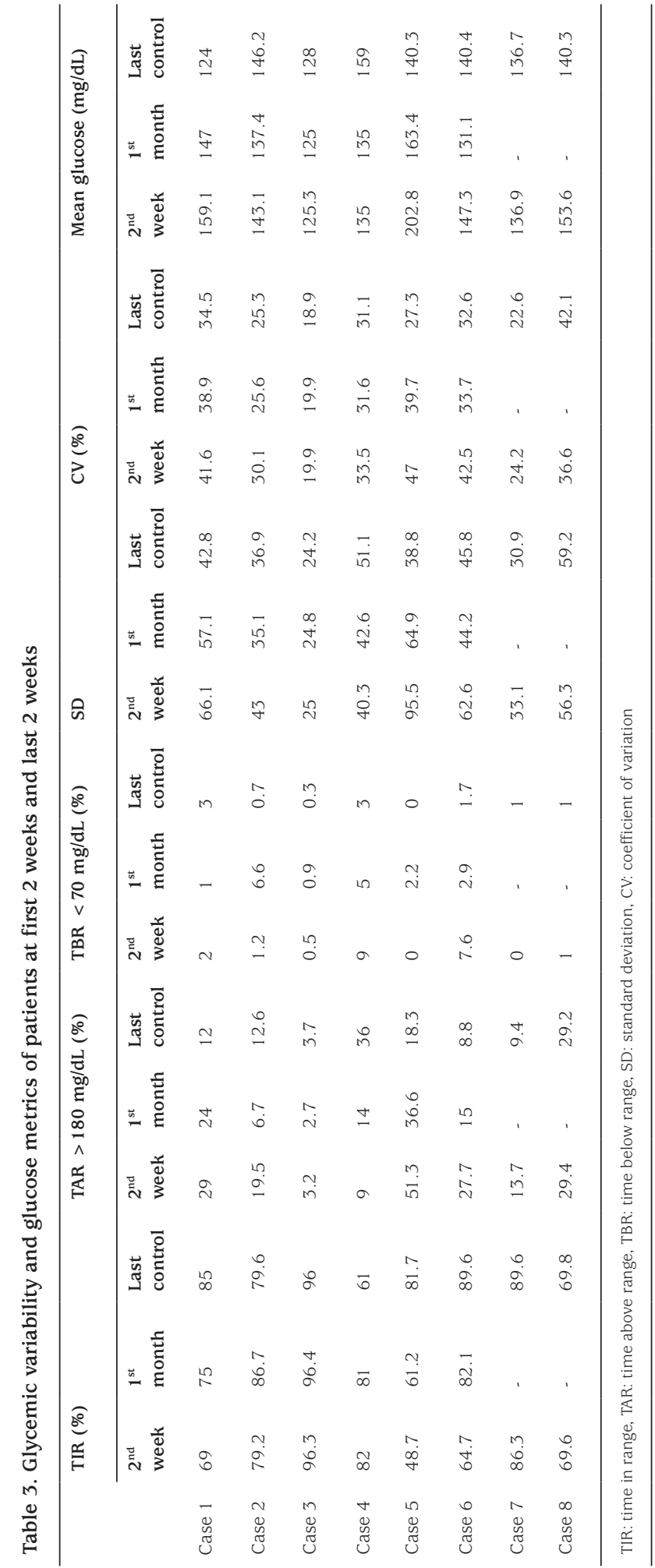


for our patients with diabetes. The "Stay at Home" order for children $<20$ years in Turkey during COVID-19 pandemic has forced a majority of the diabetes teams to provide diabetes care remotely through telehealth when possible. Moreover, parents of many children with T1D postponed their appointments, due to anxiety about contracting COVID-19 in healthcare settings.

Digital platforms are places where diabetes teams and patients can meet virtually and share and discuss downloadable data from glucometers, CGMs and insulin pumps. Furthermore, with telehealth, SMBG data and insulin doses of MDI patients can be evaluated. Telehealth can be provided through teleconferencing, telephone, text messaging, and/or e-mail. This system can provide a good alternative to the physical, and perhaps risky, routine outpatient meeting (10). However, there are still a lot of areas in Turkey, and even in the USA, with no internet access. Healthcare through telemedicine depends on the availability of wireless network systems, smart phones and regular phones for both the healthcare providers and the patients and families. Since our case group had middle-high socioeconomic status, their access to health services using telemedicine was sufficient. In order to follow-up metabolic control of our patients through telehealth, we used email and WhatsApp and received SMBG, or PDF results of CGMS or SAP and calculated glucose metrics.

The number of daily blood glucose measurements was in the desired range with $7.1 \pm 1.1$ times/day. According to a consensus report, a TIR $>70 \%$ is a recommended target for T1D (7). However, this target should be personalized and targets should be set according to the age of children. In a case report by Garg et al (11), TIR was $30 \%$ in a one-year-old patient with T1D diagnosed during the COVID-19 pandemic. Target TIR values were achieved in seven $(87.5 \%)$ patients at the last televisit and, in line with recent consensus guidlines, a TBR $<70 \mathrm{mg} / \mathrm{dL}$ ( $<3.9 \mathrm{mmol} / \mathrm{L}$ ) (level 1 hypoglycemia) of $<4 \%$ and a TBR $<54 \mathrm{mg} / \mathrm{dL}(<3.0 \mathrm{mmol} / \mathrm{L}$ ) (level 2 hypoglycemia) of $<1 \%$ were achieved in all patients (7).

GV is a metric that provides an integrated picture of postprandial hyperglycemia and hypoglycemic episodes. GV has been hypothesized to be an independent risk factor for vascular disease, independent of $\operatorname{HbA1c}(12,13,14)$. Increased GV is consistently associated with mortality and is a consistent predictor of hypoglycemia, both in prospective studies and randomized clinical trials $(15,16)$. For CV, a $36 \%$ threshold has been adopted as the primary metric to separate stable from unstable diabetes. Peters and Garg (17) reported CV values of $18 \%$ and $20.3 \%$ in two adult patients with T1DM diagnosed during COVID-19 pandemic. In our study, seven patients achieved a CV of $<36 \%$ at their last televisit.

According to the Search for Diabetes in Youth study, which includes 1396 youths aged <20 years with newly diagnosed T1D, $28 \%$ had DKA at presentation (18). In our much smaller study this rate was $75 \%$. Two of the patients had been admitted to the primary care physician and were misdiagnosed as upper respiratory tract infection and abdominal pain which may be due to lack of information of the physicians about pediatric diabetes, or their anxiety concerning COVID-19. All patients were negative for COVID-19 and the hospital stay of cases 5-8, whose diagnosis and treatment were after COVID-19 was reported in Turkey, were shortened to $8.2 \pm 2.6$ vs $19.2 \pm 8.0$ days in the patients already in hospital when the first COVID-19 case was reported. Some of the health education of cases 5-8 continued at home via telemedicine, but this difference seems to not effect glucose metrics.

\section{Conclusion}

In this study we reported managing diabetes remotely, especially in new-onset patients with T1D during this pandemic. With telehealth, optimum glycemic targets can be achieved in pediatric patients with new onset T1D. However, important limitations of telehealth systems include inability to perform a physical examination and there is no point-of-care testing available for accurate $\mathrm{HbA} 1 \mathrm{c}$ measurement. If this new way of follow-up using telehealth is to continue after the pandemic is over, it may provide substantial improvements for patients who will no longer need to attend hospital as regularly, but can also provide the benefits of daily follow-up.

\section{Ethics}

Informed Consent: Written informed consent was obtained from all participants or their parents/guardians.

Peer-review: Externally peer-reviewed.

\section{Authorship Contributions}

Surgical and Medical Practices: Ferda Evin, Damla Gökşen, Concept: Ferda Evin, Design: Ferda Evin, Data Collection or Processing: Ferda Evin, Eren Er, Aysun Ata, Yasemin Atik Altınok, Analysis or Interpretation: Ferda Evin, Eren Er, Damla Gökşen, Aysun Ata, Arzu Jalilova, Literature Search: Ferda Evin Eren Er, Damla Gökşen, Samim Özen, Şükran Darcan, Günay Demir, Writing: Ferda Evin, Damla Gökşen.

Financial Disclosure: The authors declared that this study received no financial support. 


\section{References}

1. Denham SA, Wood LE, Remsberg K. Diabetes care: provider disparities in the US Appalachian region. Rural Remote Health 2010;10:1320. Epub 2010 May 21

2. Jin $Y$, Zhu W, Yuan B, Meng $Q$. Impact of health workforce availability on health care seeking behavior of patients with diabetes mellitus in China. Int J Equity Health 2017;16:80

3. Sherr JL, Tauschmann M, Battelino T, de Bock M, Forlenza G, Roman R, Hood KK, Maahs DM. ISPAD Clinical Practice Consensus Guidelines 2018: Diabetes technologies. Pediatr Diabetes 2018;19(Suppl 27):302325.

4. Levin K, Madsen JR, Petersen I, Wanscher CE, Hangaard J. Telemedicine diabetes consultations are cost-effective, and effects on essential diabetes treatment parameters are similar to conventional treatment: 7-year results from the Svendborg Telemedicine Diabetes Project. J Diabetes Sci Technol 2013;7:587-595.

5. Izquierdo R, Morin PC, Bratt K, Moreau Z, Meyer S, Ploutz-Snyder R, Wade M, Weinstock RS. School-centered telemedicine for children with type 1 diabetes mellitus. J Pediatr 2009;155:374-379. Epub 2009 May 21

6. Lee SWH, Ooi L, Lai YK. Telemedicine for the management of glycemic control and clinical outcomes of type 1 diabetes mellitus: a systematic review and meta-analysis of randomized controlled studies. Front Pharmacol 2017;8:330.

7. Battelino T, Danne T, Bergenstal RM, Amiel SA, Beck R, Biester T, Bosi E, Buckingham BA, Cefalu WT, Close KL, Cobelli C, Dassau E, DeVries JH, Donaghue KC, Dovc K, Doyle FJ, Garg S, Grunberger G, Heller S, Heinemann L, Hirsch IB, Hovorka R, Jia W, Kordonouri O, Kovatchev B, Kowalski A, Laffel L, Levine B, Mayorov A, Mathieu C, Murphy HR, Nimri R, Nørgaard K, Parkin CG, Renard E, Rodbard D, Saboo B, Schatz D, Stoner K, Urakami T, Weinzimer SA, Phillip M. Clinical targets for continuous glucose monitoring data interpretation: recommendations from the international consensus on time in range. Diabetes Care 2019;42:1593-1603. Epub 2019 Jun 8

8. Gorbalenya AE, Baker SC, Baric RS, Baric RS, de Groot RJ, Drosten C, Gulyaeva AA, Haagmans BL, Lauber C, Leontovich AM, Neuman BW, Penzar D, Perlman S, Poon LLM, Samborskiy D, Sidorov IA, Sola I, Ziebuhr J. Severe acute respiratory syndrome-related coronavirus: the species and its viruses-a statement of the Coronavirus Study Group. BioRxiv Preprint. doi: 10.1101/2020.02.07.937862

9. Phelan AL, Katz R, Gostin LO. The novel coronavirus originating in Wuhan, China: challenges for global health governance. JAMA 2020;323:709-710.

10. Jendle J. The use of ehealth for the care of patients with diabetes in connection to the COVID-19 pandemic. J Diabetes Sci Technol 2020;14:739-740. Epub 2020 May 6

11. Garg SK, Rodbard D, Hirsch IB, Forlenza GP. Managing new-onset type 1 diabetes during the COVID-19 pandemic: challenges and opportunities. Diabetes Technol Ther 2020;22:431-439. Epub 2020 Apr 17

12. Hirsch IB. Glycemic Variability and diabetes complications: does it matter? Of course it does! Diabetes Care 2015;38:1610-1614

13. Klonoff DC, Ahn D, Drincic A. Continuous glucose monitoring: A review of the technology and clinical use. Diabetes Res Clin Pract 2017;133:178-192. Epub 2017 Sep 1

14. Colomo N, López-Siguero JP, Leiva I, Fuentes N, Rubio-Martín E, Omiste A, Guerrero M, Tapia MJ, Martín-Tejedor B, Ruiz de Adana MS, Olveira G. Relationship between glucose control, glycemic variability, and oxidative stress in children with type 1 diabetes. Endocrinol Diabetes Nutr (Engl Ed) 2019;66:540-549. (English, Spanish) Epub 2019 Mar 8

15. Marchand L, Reffet S, Vouillarmet J, Cugnet-Anceau C, Disse E, Thivolet C. The $36 \%$ coefficient of variation for glucose proposed for separating stable and labile diabetes is clinically relevant: A continuous glucose monitoring-based study in a large population of type 1 diabetes patients. Diabetes Metab 2019;45:598-600. Epub 2018 Jun 6

16. Bergenstal RM. Glycemic variability and diabetes complications: does it matter? Simply put, there are better glycemic markers! Diabetes Care 2015;38:1615-1621.

17. Peters AL, Garg SK. The Silver Lining to COVID-19: avoiding diabetic ketoacidosis admissions with telehealth. Diabetes Technol Ther 2020;22:449-453. Epub 2020 May 5

18. Duca LM, Reboussin BA, Pihoker C, Imperatore G, Saydah S, MayerDavis E, Rewers A, Dabelea D. Diabetic ketoacidosis at diagnosis of type 1 diabetes and glycemic control over time: the SEARCH for diabetes in youth study. Pediatr Diabetes 2019;20:172-179. Epub 2018 Dec 27 